\title{
Immune Tolerance Therapy for Haemophilia A Patients with Acquired Factor VIII Alloantibodies: Comprehensive Analysis of Experience ata Single Institution
}

\author{
M. P. Smith, K. J. Spence, E. L. Waters, R. Beresford-Webb, M. J . Mitc hell, J . Cuttler, \\ A. Alhaq, S. A. Brown, G. F. Savidge
}

From the Haemophilia Centre, Reference Centre for Haemostatic and Thrombotic Disorders, St Thomas' Hospital, London, UK

\section{Summary}

Eleven children with severe haemophilia A associated with the IVS 22 inversion and acquired high titre neutralising antibodies to factor VIII underwent immune tolerance induction. HLA class I and high resolution class II type is detailed for each patient. A three phase approach to immune tolerance induction was used. During phase 1, which lasted a median of six weeks, patients received factor VIII $100 \mathrm{IU} / \mathrm{kg}$ twice daily. Phase 2 comprised a factor VIII dose reduction to $100 \mathrm{IU} / \mathrm{kg}$ once daily, and continued for a median duration of 14 weeks. Subsequently 10 of the 11 patients satisfied the criteria of absent factor VIII neutralising activity by the Bethesda method, and a factor VIII elimination half life of greater than $5 \mathrm{~h}$, allowing progression to phase 3 , a further factor VIII dose reduction to $50 \mathrm{IU} / \mathrm{kg}$ three times weekly. A model for dose reduction as factor VIII tolerance evolves, based on pharmacokinetic analysis, is described.

\section{Introduction}

The development of factor VIII neutralising alloantibodies during replacement therapy in patients with severe haemophilia $\mathrm{A}$ is a treatment complication with substantial clinical and financial implications. Detected after a median of nine to 36 exposure days, the incidence of neutralising antibody development ranges from $15.6 \%$ to $28 \%$ in prospective studies of both plasma-derived and recombinant products in previously untreated patients (1-3). Inhibitory antibodies are predominantly of the IgG4 subclass (4), and often demonstrate specificity restricted to the $\mathrm{C} 2$ domain of the factor VIII light chain and/or the A2 domain of the heavy chain $(5,6)$. Low titre antibodies (less than 5 Bethesda units/ml) may spontaneously regress. High titre (greater than 10 Bethesda units/ml) and/or high responding factor VIII inhibitory antibodies, where the titre exhibits an anamnestic response to further factor VIII exposure, preclude factor VIII therapy at standard replacement doses $(7,8)$. Therapy directed at controlling haemorrhage or eradicating the inhibitor may incur substantial and unpredictable financial costs. We now report a thorough analysis of the management of 11 children with severe haemophilia A and inhibitory antibodies to factor VIII at our comprehensive care haemophilia centre. Careful attention to the timing of initiation of an immune tolerance programme together with appropriate pharmacokinetic analysis of immune tolerance induction allows a prophylactic factor VIII replacement programme to be reestablished in a highly cost-effective manner.

Correspondence to: Dr. M. P. Smith, Haemophilia Reference Centre, St Thomas' Hospital, Lambeth Palace Road, London SE1 7EH, UK Tel.: 0044171928 9292, extension 3836; FAX Number 00441714013125

\section{Patients and Methods}

Patients and immune tolerance programme. All children with severe haemophilia A (factor VIII:C less than $1 \mathrm{IU} / \mathrm{dl}$ ) registered at our centre are offered continuous prophylaxis with factor VIII replacement. This report describes the management of all children at our centre presenting with a factor VIII inhibitor over a 10 year period from 1987 to 1997. In all cases parents were counselled regarding therapeutic options, and consented to their children entering into a high dose immune tolerance induction (ITI) programme. During the preliminary phase of the immune tolerance protocol, prior to high dose factor VIII administeration, bleeding episodes were managed with inhibitor bypassing agents, either FEIBA ${ }^{\circledR}$ (Immuno) or, subsequent to its licensing in the UK, recombinant factor VIIa (NovoSeven ${ }^{\circledR}$, Novo Nordisk). Wherever possible, commencement of high dose factor VIII treatment was deferred until the neutralising antibody titre had declined to less than 10 or ideally less than 5 Bethesda units $/ \mathrm{ml}$. When this criterion was achieved, phase 1 (factor VIII $200 \mathrm{IU} / \mathrm{kg} /$ day) of the immune tolerance programme commenced. Phase 2 was defined as a dose reduction to $100 \mathrm{IU} / \mathrm{kg}$ as a daily intravenous bolus dose, and commenced after a phase 1 duration of between 4 and 12 weeks, when the neutralising antibody was undetectable by the Bethesda technique (our laboratory reports a Bethesda value of less than $1 \mathrm{BU} / \mathrm{ml}$ as negative). Phase 3 was defined as prophylactic factor VIII replacement at a dose of up to $50 \mathrm{IU} / \mathrm{kg}$ three times per week. Phase 3 commenced when pharmacokinetic analysis documented a factor VIII elimination half life of greater than five-to-six hours.

Factor VIII assay and neutralising antibody detection. Factor VIII procoagulant activity was measured on citrated plasma by a one stage clot based assay using a KC10 coagulometer. Neutralising antibodies to factor VIII were assessed on citrated plasma on a KC10 coagulometer by the Bethesda technique (9).

Factor VIII-binding assay. The radioimmuno-precipitation assay (RIPA) for detecting antibodies to factor VIII epitopes was a modification of the sensitive assay developed by Prescott et al. (10). Highly purified recombinant factor VIII (rfVIII) was generously provided by Dr. R. W. Kuhn (Bayer Coroporation, Berkely, CA, USA). Its specific activity was approximately $5,000 \mathrm{U} / \mathrm{mg}$ when fVIII activity was measured in a one-stage clotting assay. $30 \mu \mathrm{g}$ of $\mathrm{rfVIII}$ in $0.2 \mathrm{M} \mathrm{Na}$ Acetate, $5 \mathrm{mM} \mathrm{Ca}\left(\mathrm{NO}_{3}\right)_{2}$ was radiolabelled by incubation with $37 \mathrm{MBq}$ of $\mathrm{Na}^{125}$ I (Amersham International), $10 \mu \mathrm{l}$ of Lactoperoxidase beads (Worthington Biochemicals) for $10 \mathrm{~min}$ at room temperature. Free $\mathrm{Na}^{125} \mathrm{I}$ was removed on a PD10 column (Pharmacia Biotech). ${ }^{125}$ I-rfVIII had a specific activity of $33.33 \mathrm{KBq} / \mu \mathrm{g}$. ${ }^{125} \mathrm{I}-\mathrm{rfVIII}$ was diluted to $1.6 \mathrm{ug} / \mathrm{ml}$ in $20 \mathrm{mM}$ Tris, $150 \mathrm{mM} \mathrm{NaCl}, 1 \% \mathrm{BSA}, \mathrm{pH} 7.4$ (TBS-BSA). $10 \mu \mathrm{l}$ (approx 30,000 cpm) was added to $50 \mu$ of diluted plasma $(1: 2$ in TBS-BSA) in duplicate and incubated at $4^{\circ} \mathrm{C}$ for $18-20 \mathrm{~h}$. The ${ }^{125} \mathrm{I}$-rfVIII-anti-fVIII immune complexes were then precipitated by the addition of $150 \mu \mathrm{l}$ of 1 in 3 dilution of protein G Sepharose (Gammabind, Pharmacia Biotech) in TBS-BSA with incubation on a rotary shaker for $3 \mathrm{~h}$ at $4^{\circ} \mathrm{C}$. The precipitate was then washed 3 times with $1 \mathrm{ml}$ of TBS, $0.05 \%$ Tween 20 (Bio-Rad Laboratories) with brief centrifugation to pellet the Protein G Sepharose. The amount of ${ }^{125}$ I-rfVIII precipitated ('bound' activity) was then quantified by counting on a gamma counter. Non-specific activity was assessed from a buffer control. The results are represented as \% bind- 
ing: [(Bound minus Non-specific activity)/Total] $\times 100$. A normal range for this technique of less than $0.96 \%$ was established by processing plasma samples from eighty four healthy blood donors. The mean \% binding in this group was $0.104 \%$, standard deviation $0.43 \%$, mean coefficient of variability $19 \%$.

A europium-based non-radioactive method for the detection of factor VIII binding antibody was developed. Lyophilised recombinant factor VIII (Recombinate $^{\mathrm{TM}}$, Baxter Hyland $\left.{ }^{\circledR}\right)$ was dissolved in buffer $\left(\mathrm{NaHCO}_{3} 0.1 \mathrm{M}\right.$ mixed with $\mathrm{Na}_{2} \mathrm{CO}_{3} 0.1 \mathrm{M}$ to $\mathrm{pH} 9.6$ ) to $25 \mathrm{IU} / \mathrm{ml}$ and incubated in microtitre plates at $4^{\circ} \mathrm{C}$ overnight. After four washes with buffer in an automated plate washer, wells were blocked with $1 \%$ BSA (Sigma) for $30 \mathrm{~min}$ at room temperature and washed again. Dilutions of patient and control plasmas were then incubated in wells at $4^{\circ} \mathrm{C}$ overnight. After four further washes, $100 \mu \mathrm{l}$ of europium labelled anti-human $\operatorname{IgG}$ (EG \& G Wallac), diluted 1 in 500, was added to each well and incubated at $4^{\circ} \mathrm{C}$ overnight. Plates were then washed four times in wash concentrate and $200 \mu \mathrm{l}$ of enhancing solution (EG \& G Wallac) added to each well. After storage in the dark for $10 \mathrm{~min}$, plates were read using a time-resolved fluorescence reader (Arcus, EG \& G Wallac) and reported in Time Resolved Fluorescence (TRF) units. A normal range for this technique of less than $39.4 \times 10^{3}$ TRF units was established by processing plasma samples from eighty seven healthy blood donors. The mean factor VIII-binding activity in this group was $20 \times 10^{3}$ TRF units, standard deviation $9.7 \times 10^{3}$ TRF units, mean coefficient of variability $8 \%$.

Pharmacokinetic analysis. Studies of factor VIII pharmacokinetics were performed during and at intervals after high dose factor VIII therapy for induction of immune tolerance. After a four day washout period, blood samples were taken before and at intervals after a $50 \mathrm{IU} / \mathrm{kg}$ factor VIII bolus dose, until measured factor VIII procoagulant activity had returned to native baseline levels. The factor VIII elimination half life $\left(\mathrm{t}_{1 / 2 \beta}\right)$ was assessed using a pharmacokinetic analytical programme (PKAnalyst, MicroMath ${ }^{\circledR}$ Scientific Software, Salt Lake City, UT), with data fitting based on a two compartment model.

Statistical analysis. Correlation coefficients between $\mathrm{t}_{1 / 2 \beta}$ values and factor VIII binding by the europium based assay and by the RIPA method were calculated using the Pearson's product-moment correlation.

IVS 22 inversion method and HLA typing. DNA was extracted from 1-3 mls of whole blood by standard techniques (Puregene ${ }^{\mathrm{TM}}$, Flowgen, UK). DNA $(8 \mu \mathrm{g})$ was digested with $\mathrm{Bcl} \mathrm{I}$ (Promega, Madison, USA) for $6 \mathrm{~h}$ at $50^{\circ} \mathrm{C}$, and electrophoresed on a $0.5 \%$ agarose gel (Promega, Madison, USA) at $80 \mathrm{v}$ overnight before being Southern blotted onto Hybond N (Amersham, UK) and UV cross-linked. Filters were prehybridized in $2 \times$ SSC, $2 \times$ Denhardt's, $0.5 \%$ SDS, and $100 \mu \mathrm{g} / \mathrm{ml}$ Genebloc (Advanced Biotechnologies, Epsom, UK) at $68^{\circ} \mathrm{C}$ for $2 \mathrm{~h}$, and then hybridized to a ${ }^{32} \mathrm{P}$ labelled (Multiprimer DNA labelling kit, Amersham, UK) EcoRI/Sac I fragment of p482.6 $6^{1}$ in $2 \times$ SSC, $0.5 \%$ SDS, $100 \mu \mathrm{g} / \mathrm{ml} \mathrm{Genebloc} \mathrm{for} 4 \mathrm{~h}$ at $68^{\circ} \mathrm{C}$. Filters were washed in $0.2 \times \mathrm{SSC}, 0.1 \%$ SDS at $65^{\circ} \mathrm{C}$ for $30 \mathrm{~min}$, then $0.2 \times \mathrm{SSC}$ for $30 \mathrm{~min}$ prior at autoradiography (11). EDTA blood samples were collected for tissue typing at the National Blood Service reference laboratory. Low resolution class I typing was performed by serological methods. High resolution class II typing was performed by PCR-SSP.

\section{Results}

As a result of either routine three monthly screening for neutralising factor VIII antibodies or of investigation into reduced haemostatic control, 11 children, most with high titre inhibitors, were identified between January 1987 and December 1996. The patients had a median age of 2 years (range 0.8-4.5 years) at the time of inhibitor detection, after a median of 20 exposure days (range 4-37). Patient demographic details are shown in Table 1. Most children were of British Caucasian origin, except patients 2 and 10, who were of African extraction and Asian extraction respectively. Only two patients had a documented maximum inhibitor titre of less than $10 \mathrm{BU} / \mathrm{ml}$ (patients 1 and 9). In both these cases, the potential for anamnestic response in inhibitor titre was avoided by immediate conversion to recombinant factor VIIa as a therapeutic modality to control bleeding. Molecular analysis confirmed
Table 1 Patient characteristics: Acquired factor VIII inhibitor (IN)

\begin{tabular}{|c|c|c|c|c|c|c|}
\hline $\begin{array}{l}\text { Patient } \\
\text { ID }\end{array}$ & $\begin{array}{c}\text { Baseline } \\
\text { factor VIII } \\
\text { (IU/dl) }\end{array}$ & $\begin{array}{c}\text { Factor VIII } \\
\text { genetic mutation }\end{array}$ & $\begin{array}{l}\text { Factor VIII } \\
\text { concentrate } \\
\text { prior to IN } \\
\text { diagnosis }\end{array}$ & $\begin{array}{c}\text { Age at iN } \\
\text { diagnosis } \\
\text { (years) }\end{array}$ & $\begin{array}{c}\text { Exposure } \\
\text { days at } \\
\text { IN onset }\end{array}$ & $\begin{array}{l}\text { Maximum } \\
\text { IN titre } \\
\text { prior to ITI } \\
(\mathrm{BU} / \mathrm{ml})\end{array}$ \\
\hline 1 & $<1$ & IVS 22 Inversion & recombinant & 0.8 & 7 & 9 \\
\hline 2 & $<1$ & IVS 22 Inversion & plasma-derived* & 4.5 & 27 & 122 \\
\hline 3 & $<1$ & IVS 22 Inversion & plasma-derived & 1.8 & 32 & 14 \\
\hline 4 & $<1$ & IVS 22 Inversion & recombinant & 2.0 & 9 & 31 \\
\hline 5 & $<1$ & IVS 22 Inversion & plasma-derived ${ }^{*}$ & 1.3 & 37 & 34 \\
\hline 6 & $<1$ & IVS 22 lnversion & plasma-derived ${ }^{*}$ & 2.5 & 30 & 87 \\
\hline 7 & $<\mathrm{I}$ & IVS 22 Inversion & plasma-derived" & 3.5 & 20 & 14 \\
\hline 8 & $<1$ & IVS 22 Inversion & plasma-derived" & 2.8 & 12 & 23 \\
\hline 9 & $<1$ & IVS 22 Inversion & recombinant & 0.9 & 4 & 9 \\
\hline 10 & $<1$ & IVS 22 Inversion & recombinant & 2.0 & 8 & 73 \\
\hline 11 & $<1$ & IVS 22 Inversion & recombinant & 2.0 & 24 & 11 \\
\hline
\end{tabular}

Table 2 Patient HLA genotype

\begin{tabular}{ccccccc}
\hline Patient & HLA A & HLA B & HLA Cw & DRB1* & DQA1* & DQB1* \\
\hline 1 & $2,68(28)$ & $14,62(15)$ & $8,9(3)$ & 1301,1303 & 0103,0501 & 0603,0301 \\
2 & $2,68(28)$ & $51(5), 71(70)$ & 10,14 & 1301,0301 & 0103,0501 & $02,0603(7)$ \\
3 & $1,24(9)$ & $7,44(12)$ & 5,7 & 0901,1201 & 0302, & $0303,0301 / 4$ \\
& & & & & $05011 / 13$ & \\
4 & 1,11 & $55(22)$ & $7,10(3)$ & 0301,0407 & 0303, & $0201 / 2$, \\
& & & & & $05011 / 13$ & $0301 / 4$ \\
5 & $2,29(19)$ & 7,13 & 6,7 & 1501,07 & 0102,0201 & 0602,02 \\
6 & $11,24(9)$ & $44(12), 51(5)$ & 5,15 & 0408,1501 & 0102,0302 & 0301,0602 \\
7 & $11,24(9)$ & $44(12), 51(5)$ & 5,15 & 0408,1501 & 0102,0302 & 0301,0602 \\
8 & $23(9), 32(19)$ & $35,44(12)$ & $4,-$ & $0301 / 4$, & 0103, & $0201 / 2,0603$ \\
& & & & $1301 / 8 / 22$ & $05011 / 13-$ & \\
9 & 2,3 & $\mathbf{8 , 5 0 ( 2 1 )}$ & 6,7 & 0301,07 & 0201,0501 & $0201,0202 / 3$ \\
10 & $1,68(28)$ & $44(12), 52(5)$ & 5,12 & 1101,1104 & $0501, \mathrm{X}$ & $0301, \mathrm{X}$ \\
11 & $3,31(19)$ & 7,27 & 2,7 & 0401,1501 & 0102,0302 & 0302,0602 \\
\hline
\end{tabular}

Table 3 Immune tolerance (IT) programme results

\begin{tabular}{cccccc}
\hline Patient & $\begin{array}{c}\text { IN titre at start of } \\
\text { Phase 1 factor VIII } \\
\text { administration } \\
(\mathrm{BU} / \mathrm{ml})\end{array}$ & $\begin{array}{c}\text { Duration of Phase I } \\
\text { Factor VIII 200 } \\
\text { IU/kg/day } \\
\text { (weeks) }\end{array}$ & $\begin{array}{c}\mathfrak{t}_{1 / 2 \beta} \text { and recovery at 12 } \\
\text { weeks into Phase 2 of } \\
\text { ITI programme } \\
\text { (hours, }\end{array}$ & $\begin{array}{c}\text { Duration of Phase 2 } \\
\text { Factor VIII 100 } \\
\text { IU/kg/day } \\
\text { (weeks) }\end{array}$ \\
\hline 1 & 9.0 & 5 & 5.0, & 45 & 13 \\
2 & 1.6 & 5 & 7.0, & 92 & 22 \\
3 & 2.3 & 4 & 12.5, & 85 & 12 \\
4 & 9.0 & 4 & 6.0, & 54 & 14 \\
5 & 2.9 & 12 & 5.3, & 46 & 12 \\
6 & 0.6 & 7 & 8.4, & 80 & 16 \\
7 & 0.7 & 7 & 0.2, & 35 & 120 \\
8 & 2.6 & 4 & $\mathbf{8 . 0 ,}$ & 72 & 8 \\
9 & 7.1 & 8 & 6.2, & 37 & 20 \\
10 & 20 & 6 & 5.7, & 50 & 12 \\
11 & 3 & 8 & 5.8, & 100 & 16 \\
\hline
\end{tabular}

that the IVS 22 inversion was the causative mutation in all cases. HLA genotype of each patient is shown in Table 2. Patients 6 and 7 were brothers, and HLA identical. All 11 consecutive patients proceeded to an IT programme, the details of which are shown in Table 3. Unless the clinical condition necessitated earlier intervention, phase 1 of the programme was delayed until the inhibitor titre had declined to as low a level as possible. In most cases the inhibitor titre at the onset of phase 1 was less than $5 \mathrm{BU} / \mathrm{ml}$ (median 2.9, range 0.6-20). Five patients (ID 2, 5, 6, 7 and 8) were diagnosed with a factor VIII inhibitory antibody prior to 1994, when our centre started to perform immune tolerance induction procedures. These 5 patients had delays of 6.5, 4.0, 5.5, 2.5 and 3.5 years respectively between diagnosis and start of immune tolerance induction. Other patients had a median interval of 3 weeks (range 2-52) between inhibitor diagnosis and start of immune tolerance induction. There were six patients receiving monoclonal purified, high purity, plasma derived factor VIII concentrate at the time of inhibitor diagnosis. Immune tolerance was established with the same plasma derived product in one of these (patient 5) and with a recombinant product in the other five (patients 2, 3, 6, 7 and 8). The other five patients $(1,4,9$, 10 and 11) who had always received recombinant factor VIII were tolerised with the same product. Phase 1 commenced with continuous factor VIII infusion to provide perioperative haemostatic control for inser- 
Table 4 Phase 3 of immune tolerance programme: Pharmacokinetic data and factor VIII-binding alloantibody results by radio-immuno-assay (RIA) and Time Resolved Fluorescence (TRF) techniques. na: not available; NR: normal range

\begin{tabular}{cccccc}
\hline Patient & $\begin{array}{c}\text { Time on phase 3 } \\
\text { (years) }\end{array}$ & $\begin{array}{l}\text { Current Factor VIII } \\
\mathrm{t}_{1 / 23} \text { (hours) and recovery (\%) }\end{array}$ & $\begin{array}{c}\text { RIPA } \\
(\% \text { binding) } \\
\text { NR<0.96\% }\end{array}$ & $\begin{array}{c}\text { Factor VII binding } \\
\left(\text { TRF units } x 10^{3}\right) \\
\text { NR }<39.4 \times 10^{3}\end{array}$ \\
\hline 1 & 0.3 & 5.0 & 58 & 4.46 & 772 \\
2 & 2.0 & 10.2 & 80 & 0.56 & 169 \\
3 & 2.0 & 12.1 & 98 & 0.04 & 50 \\
4 & 0.3 & 8.0 & 60 & 4.10 & 182 \\
5 & 2.5 & 8.6 & 92 & 3.59 & 305 \\
6 & 1.8 & 10.4 & 80 & 1.70 & 115 \\
7 & 0.3 & 4.5 & 43 & 3.22 & 259 \\
8 & 2.4 & 8.6 & 100 & 0.00 & 54 \\
9 & 0.8 & 12.7 & 67 & 1.9 & 240 \\
10 & 1.3 & 7.0 & 54 & 7.72 & na \\
11 & 1.9 & 7.0 & 100 & 0.34 & 107 \\
\hline
\end{tabular}

tion of a central venous access device. With this regime, measured factor VIII procoagulant activity in all cases was intentionally greater than $100 \mathrm{IU} / \mathrm{dl}$ during the first week of high dose factor VIII therapy. Patient 10 , who commenced phase 1 with an inhibitor titre of $20 \mathrm{BU} / \mathrm{ml}$, required a factor VIII infusion of $50 \mathrm{IU} / \mathrm{kg} / \mathrm{h}$ to achieve this. Phase 1 was a median of 6 weeks duration (range 4-12). The timing of dose reduction to phase 2 (from twice daily to once daily factor VIII $100 \mathrm{IU} / \mathrm{kg}$ ) was based on the inhibitory antibody titre being undetectable by the Bethesda technique and measured factor VIII recovery of greater than 60-80\%. Pharmacokinetic assessment was an important consideration in the timing of dose reduction from phase 2 to phase 3 (factor VIII $100 \mathrm{IU} / \mathrm{kg} /$ day to $50 \mathrm{IU} / \mathrm{kg}$ three times per week). Pharmacokinetic analysis performed at 8-12 weeks into phase 2 showed a factor VIII $t_{1 / 2 \beta}$ of at least $5 \mathrm{~h}$ in all cases except patient 7 , whose $\mathrm{t}_{1 / 2 \beta}$ was $0.2 \mathrm{~h}$. Patient 7 was continued on daily factor VIII prophylaxis (2000 IU) for 30 months before his $\mathrm{t}_{1 / 2 \beta}$ increased from 1.8 to $4.5 \mathrm{~h}$, at which time he was moved to phase 3 without clinical deterioration. Patients 2 and 9 were continued on daily treatment despite suitable $t_{1 / 2 \beta}$ for a total of 22 and 20 weeks respectively to allow inflammation in target joints to fully settle in the absence of bleeding. Results of factor VIII binding studies, as assessed by both the RIPA test and the Time Resolved Fluorescence (TRF) method, on samples taken at variable time points in phase 3 of the IT programme are shown in Table 4, together with corresponding $\mathrm{t}_{1 / 2 \beta}$ results. These samples all showed no detectable inhibitor by the Bethesda technique. The $\mathrm{t}_{1 / 2 \beta}$ values showed a correlation coefficient of -0.498 ( $p=0.119)$ with \% alloantibody binding by the RIPA technique, and a correlation coefficient of $-0.528(\mathrm{p}=0.117)$ with factor VIII binding by the TRF method. The two methods of detecting factor VIII binding activity, RIPA and TRF, showed a correlation coefficient of 0.734 $(p=0.016)$. There were no adverse events, in particular no infective or thrombotic complications, related to central lines in any of the $11 \mathrm{pa}-$ tients. All boys continue prophylactic factor VIII replacement therapy.

\section{Disc ussion}

The pathogenesis of development of neutralising factor VIII antibodies in haemophilia A patients is unclear. Attempts at defining the immune responsiveness of haemophiliacs through documentation of HLA type have not yet identified strong predictors for inhibitor development (12), possibly because of the high degree of heterogeneity of both class II HLA type and the individual genetic mutations causing haemophilia. Oldenburg et al. (13) studied a group of severe haemophilia A patients with a single causative mutation, inversion of IVS 22, and determined HLA genotype. They found the haplotype HLA-A3, B7, C7, DQA0102, DQB0602, DR15 was weakly correlated to inhibitor development. All patients in our report had inversion of IVS 22 as their causative mutation. Our data are consistent with the findings of Oldenburg et al. (13), and expand on the database detailed as an appendix to their paper. In our patients, the three alleles HLA-DRB1*1501, DQA $1 * 0102$ and DQB $1 * 0602$ each showed a frequency of $36 \%$. These alleles form a conserved haplotype, and have been reported to be present at increased frequency in the patient group with IVS 22 inversion and acquired inhibitors to factor VIII $(12,13)$.

Protocols for immune tolerance induction (ITI) in haemophiliacs with neutralising factor VIII antibodies have utilised low (14) and high $(15,16)$ dose factor VIII replacement. Multivariate analysis of the International Immune Tolerance Registry has shown that inhibitor titre of greater than $10 \mathrm{BU} / \mathrm{ml}$ at the start of immune tolerance induction, and high factor VIII dosage $(\geq 100 \mathrm{IU} / \mathrm{kg} /$ day) independently predict for a high probability of inducing immune tolerance (17). However, limitations to the implementation of ITI programmes include poorly defined guidelines for monitoring the evolution of IT, limited dose-adjustment criteria as IT is established, and lack of systematic collection of quality of life outcome data to facilitate cost-benefit analysis. Our results are in accord with the International Registry findings, and in addition they provide a framework for factor VIII dose management throughout the ITI programme, through to resumption of a prophylactic replacement schedule, based on pharmacokinetic data. Contentious issues regarding ITI therapy include choice of factor VIII dose for ITI, definition of when tolerance is achieved, and what constitutes a successful outcome. In addition, there is no uniform practise regarding whether a patient is subsequently placed on a programme of prophylactic factor VIII replacement. It is generally accepted that high dose programmes will achieve a degree of tolerance more rapidly than low dose regimes, but at a higher financial cost. During phase 3, when factor VIII neutralising antibodies are undetectable by the Bethesda method, we have shown a progressive prolongation of $t_{1 / 2 \beta}$. This observation indicates that immune tolerance is not an 'all or nothing' phenomenon. Rather, tolerance to regularly infused factor VIII antigen continues to evolve long after the Bethesda method fails to detect a neutralising antibody. Our approach to ITI emphasises this important concept, and illustrates that high and low dose protocols need not be mutually exclusive. Phases 1 and 2 of our protocol (200 and $100 \mathrm{IU} / \mathrm{kg} /$ day respectively) serve to induce a degree of tolerance sufficient to improve the pharmacokinetic profile of administered factor VIII. Implementation of phase 3 at a time when factor VIII pharmacokinetics are satisfactory represents a switch to a low dose regime, at a time when such a dose effectively prevents spontaneous haemorrhage. The concept that IT continues to evolve during phase 3 is compatible with the observations by Dazzi et al. (18) that the titre of factor VIII binding antibody does influence the $t_{1 / 2 \beta}$ even when the Bethesda method fails to detect a neutralising antibody.

The dose reduction from phase 1 to phase 2 was largely empirical, facilitating a $50 \%$ reduction in factor VIII consumption. The delay to therapy inherent in accurate assessment of factor VIII $t_{1 / 2 \beta}$ at a median of 12 weeks into phase 2 appeared not to have deleterious effects on success of the programme, and provided valuable data to justify a further dose reduction to phase 3 . The RIPA technique is a very sensitive indicator of the presence of factor VIII-binding activity and is not necessarily a reflection of active site blockade. The limitation of the RIPA data in this study is that samples were not taken serially before and at intervals during ITI in all patients. Nevertheless, results do indicate the presence of factor VIII binding antibodies in most patients after ITI, when factor VIII neutralising activity as assessed by the Bethesda technique is not detected. This factor VIII binding activity was absent in a group of 7 severe haemophilia A controls on routine prophylactic treatment, matched for age and causative genetic mutation (data not shown). 
Presence of both factor VIII-binding and specific anti-idiotypic antibodies have been documented in desensitised inhibitor patients (19) and people without haemophilia (20), and do not necessarily reflect factor VIII neutralising activity. We have presented factor VIII binding results as assessed by RIPA and Time Resolved Fluorescence techniques, together with corresponding pharmacokinetic data, and showed that these techniques can provide complimentary information on the biological fate of infused factor VIII. The two methods measuring factor VIII binding activity were positively correlated with each other and negatively correlated with $t_{1 / 2 \beta}$, although study of a larger inhibitor patient group would be required to demonstrate statistical significance.

In conclusion our findings provide a framework for development of dose adjustment guidelines throughout an ITI programme, based on pharmacokinetic assessment. Factor VIII binding assays using the RIPA and/or Time Resolved Fluorescence techniques may provide useful information, particularly if performed serially, and interpreted in conjunction with pharmacokinetic data. A comprehensive approach to induction of immune tolerance, including systematic assessment of impact on quality of life is essential to justify the cost effectiveness of ITI programmes.

\section{References}

1. Kreuz W, Escuriola-Ettingshausen C, Martinez-Saguer I, Güngör T, Kornhuber B. Epidemiology of inhibitors in Haemophilia A. Vox Sanguinis 1996; 70 (suppl 1): 2-8.

2. Ehrenforth S, Kreuz W, Scharrer I, Linde R, Funk M, Güngör T, Krackhardt B, Kornhuber B. Incidence of development of factor VIII and factor IX inhibitors in haemophiliacs. Lancet 1992; 339: 594-8.

3. Lusher J, Arkin S, Abildgaard D, Hurst D. Recombinant factor VIII (Kogenate) treatment of previously untreated patients (PUPS) with haemophilia A: Update of safety, efficacy and inhibitor development after seven study years. Thromb Haemost 1997 (abstr); June suppl: 162.

4. Kavanaugh ML, Wood CN, Davidson JF. The immunological characterization of human antibodies to factor VIII isolated by immuno-affinity chromatography. Thromb Haemost 1981; 45: 60-4.

5. Scandella D, de Graaf Mahoney S, Mattingly M, Roeder D, Timmons L, Fulcher CA. Epitope mapping of human factor VIII inhibitor antibodies by deletion analysis of factor VIII fragments expressed in Escherichia coli. Proc Natl Acad Sci USA 1988; 85: 6152-6.

6. Scandella D. Human anti-factor VIII antibodies: Epitope localization and inhibitory function. Vox Sanguinis 1996; 70 (suppl): 9-14.

7. Feinstein DI. Acquired disorders of haemostasis. In: Haemostasis and Thrombosis: Basic Principles and Practise, Third Edition. Colman RW, Hirsh J, Marder VJ, Salzman EW (eds). Philadelphia: JB Lippincott Company 1994; 881-905.
8. Ingerslev J, Freidman D, Gastineau D, Gilchrist G, Johnsson H, Lucas G, McPherson J, Preston E, Scheibel E, Shuman M. Major surgery in haemophilic patients with inhibitors using recombinant factor VIIa. Haemostasis 1996; 26 (suppl 1): 118-23.

9. Kasper CK, Aledort LM, Counts RB, Edson JR, Fratantoni J, Green D, Hampton JW, Hilgartner MW, Lazerson J, Levine PH, McMillan CW, Pool JG, Shapiro NR, van Eys J. A more uniform measurement of factor VIII inhibitors. Thromb Diath Haemorrhag 1975; 34: 875-6.

10. Prescott R, Nakai H, Saenko EL, Scharrer I, Nilsson IM, Humphries JE, Hurst D, Bray G, Scandella D. The inhibitor antibody response is more complex in hemophilia A patients than in most nonhemophiliacs with factor VIII antibodies. Blood 1997; 89: 3663-71.

11. Levinson B, Kenwrick S, Lakich D, Hammonds G, Gitschier J. A transcribed gene in an intron of the human factor VIII gene. Genomics 1990; 7: $1-11$.

12. Hay CRM, Ollier W, Pepper L, Cumming A, Keeney S, Goodeve AC, Colvin BT, Hill FGH, Preston FE, Peake IR, from the UKHCDO Working Party. HLA class II profile: a weak determinant of factor VIII inhibitor development in severe haemoplilia A. Thromb Haemost 1997; 77: 234-7.

13. Oldenburg J, Picard JK, Schwaab R, Brackmann HH, Tuddenham EGD, Simpson E. HLA genotype of patients with severe haemophilia A due to intron 22 inversion with and without inhibitors of factor VIII. Thromb Haemost 1997; 77: 238-42.

14. Van Leeuwen EF, Mauser-Bunschoten EP, van Dijken PJ, Kok AJ, Sjamsedin-Visset EJM, Sixma JJ. Disappearance of factor VIII:C antibodies in patients with haemophilia A upon frequent administration of factor VIII in intermediate or low dose. Brit J Haematol 1986; 64: 291-7.

15. Brackmann HH, Oldenburg J, Schwaab R. Immune tolerance for the treatment of factor VIII inhibitors - twenty years' 'Bonn protocol.' Vox Sang 1996; 70 (suppl): 30-5.

16. Nilsson IM, Berntorp E, Zetterall O. Induction of immune tolerance in patients with haemophilia and antibodies to factor VIII by combined treatment with intravenous IgG, cyclophosphamide, and factor VIII. N Eng J Med 1988; 31: 947-50.

17. Mariani G, Ghirardini A, Bellocco R. Immune tolerance in haemophilia principal results from the International Registry. Report of the factor VIII and IX subcommittee. Thromb Haemost 1994; 72: 155-8.

18. Dazzi F, Tison T, Vianello F, Radossi P, Zerbinati P, Carraro P, Poletti A, Girolami A. High incidence of anti-FVIII antibodies against non-coagulant epitopes in haemophilia A patients: a possible role for the half-life of transfused FVIII. Brit J Haematol 1996; 93: 688-93.

19. Gilles JG, Desqueper B, Lenk H, Vermylen J, Saint-Remy JM. Neutralising antiidiotypic antibodies to factor VIII inhibitors after desentization in patients with haemophilia A. J Clin Invest 1996; 97: 1382-8.

20. Gilles JG, Saint-Remy JM. Healthy subjects produce both anti-factor VIII and specific anti-idiotypic antibodies. J Clin Invest 1994; 94: 1496-505.

Received May 13, 1998 Accepted after revision September 19, 1998 